\title{
RESTAURANTE POPULAR: A FOME DE CIDADANIA E O DIREITO HUMANO A ALIMENTAÇÃO
}

\author{
Nathalia Delfavero Batista, Korina Aparecida Teixeira Ferreira da Costa \\ Universidade do Oeste Paulista - UNOESTE, Presidente Prudente, SP. E-mail: nathaliadelf@hotmail.com
}

\section{RESUMO}

A fim de buscar por melhores condições na vida da população e promover a dignidade humana, foi realizado um estudo de implantação de uma unidade de Restaurante Popular na cidade de Presidente Prudente, considerando o impacto que a atuação dos mesmos promove na sociedade, no cenário das desigualdades sociais e na falta de equipamento de mesmo caráter na região. O principal objetivo é a garantia de um direito básico e fundamental, buscando atender à necessidade humana de acesso a refeições diárias a um valor acessível, contemplando principalmente a parcela da população mais vulnerável socialmente. A partir de embasamentos teóricos que sustenta e aprimora o entendimento sobre o assunto, através de estudos e análises de antecedentes projetuais, e após levantamentos técnicos, o projeto tem seu início na busca por uma localização que concentre possíveis usuários, resultando em uma pré-existência próxima ao quadrilátero central. Assim, se apresentando como uma política social de combate à fome, o projeto se concretiza em um espaço de representação social, ajustado a realidade humana do público alvo e pensado de maneira que possa estimular as sensações afetivas ao local, seja de pertencimento, de segurança e proteção, que o equipamento possa ser entendido além de um espaço coletivo, mas como um espaço político, garantindo aos usuários a experiência da emancipação social por meio da obtenção do direito à alimentação. Indo contra a privação da liberdade de sobrevivência e a dor da fome, o Restaurante Popular soma socialmente e economicamente para a cidade de Presidente Pudente.

Descritores: Combate à fome. Presidente Prudente. Restaurante Popular. Vulnerabilidade Social.

\section{POPULAR RESTAURANT: CITIZENSHIP HUNGER AND THE HUMAN RIGHT TO FOOD}

\begin{abstract}
In order to seek better conditions in the life of the population and promote human dignity, a study was carried out to implement a Popular Restaurant unit in the city of Presidente Prudente, considering the impact that their performance has on society, in the scenario of social inequalities and the lack of similar equipment in the region. The main objective is to guarantee a basic and fundamental right, seeking to meet the human need for access to affordable daily meals, covering mainly the most socially vulnerable population. Based on theoretical foundations that sustain and improve the understanding on the subject, through studies and analysis of project antecedents, and after technical surveys, the project has its beginning in the search for a location that concentrates possible users, resulting in a pre-existence close to the central quadrilateral. Thus, presenting itself as a social policy to fight hunger, the project materializes in a space of social representation, adjusted to the human reality of the target audience and thought in a way that can stimulate the affective feelings to the place, be it of belonging, of security and protection, that the equipment can be understood beyond a collective space, but as a political space, guaranteeing users the experience of social emancipation through obtaining the right to food. Going against the deprivation of freedom of survival and the pain of hunger, the Popular Restaurant adds socially and economically to the city of Presidente Pudente.
\end{abstract}

Keywords: Fight against hunger. Presidente Prudente. Popular Restaurant. Social Vulnerability. 


\section{INTRODUÇÃO}

Existem diversas formas de privação de liberdade que englobam pessoas por todo mundo, e de acordo com Sen (2000) a fome coletiva é uma delas, a qual nega a muitos a liberdade básica de sobrevivência. Dessa forma, não tem como falarmos da fome sem falar da pobreza, a qual é resultado do sistema capitalista em que vivemos, um fenômeno multidimensional e de tamanha complexidade, onde dinheiro é privilegiado em contraposição ao bem-estar social, privando uma considerável parcela da população do acesso à alimentação (PINHEIRO; CARVALHO, 2010; ROSANELI, et al, 2015).

Como consequência, estes se veem condenados ao insuficiente desenvolvimento físico, social e psicológico, além de estarem reféns da condição de extrema miséria por possuírem oportunidades desiguais referentes a educação, saúde e participação política, de modo que as manifestações biológicas da fome, desnutrição ou obesidade, bem como o modo de comer, viver, adoecer e falecer da sociedade é evidenciado como um reflexo da submissão da população aos ditames do capital (PINHEIRO; CARVALHO, 2010; ROSANELI, et al, 2015).

Além de prejuízos físicos, a fome pode ocasionar danos neurológicos irreversíveis, acompanhados de distúrbios nas áreas emocionais e cognitivas. Assim, estando debilitado físico e mentalmente o ser humano que carece de uma alimentação adequada se torna vulnerável, tendo suas funções orgânicas e aptidões prejudicadas para realizar um trabalho. De acordo com Rosaneli et al. (2015), é na complexidade funcional e fisiológica que se presuma que a "dor da fome" não seja compreendida aos que dela não padecem, sendo apenas presenciadas e não sentida. ROSANELI, et al, 2015).

Com isso se faz preciso a atuação do Estado ao desenvolver políticas sociais, as quais devem possuir como fundamento 0 entendimento da determinação social, sendo assumidas como responsabilidade do Estado e incorporadas às políticas de caráter intersetorial que rompam com a separação entre o econômico e o social (PINHEIRO; CARVALHO, 2010). Estas, devem procurar nivelar as oportunidades entre as camadas mais altas e baixas da sociedade, dando fim a continuidade do ciclo da pobreza (BELIK; GROSSI, 2003).

Dito isso, é necessário contextualizar sobre as políticas públicas sociais no Brasil, as quais foram fundadas a partir do desdobramento das lutas de classes se apresentando como o caminho para a materialização dos direitos e necessidades humanas e diminuição das desigualdades. A partir delas, e ao tratarmos da questão da fome especificamente, um extenso caminho foi percorrido até a e concepção de um marco legal e jurídico que viabilizasse a sustentação de ações no campo da Segurança Alimentar e Nutricional, na expectativa de mitigar os problemas mais severos da fome no país e tornar o acesso à alimentação um direito humano permanente e universal (PADRÃO, 2018).

Ao longo dos anos o Governo Federal implantou ações com foco no abastecimento, na distribuição, no assistencialismo, no estímulo à produção de alimentos, na universalização das políticas sociais e na criação de um sistema de proteção social, sendo estas fundamentais para a garantia do direito humano à alimentação adequada, de forma igualitária para toda a população (PINHEIRO; CARVALHO, 2010 ; MOTA, 2015). No entanto, de acordo com Valente (2003) mais do que um projeto de combate à fome, o Brasil precisava de uma política nacional que promovesse de forma direta a alimentação, nutrição e modos de vida saudáveis, contribuindo para o desenvolvimento humano sustentável, e promovendo a dignidade humana ROSANELI, et al, 2015).

Nesse contexto, como uma ação justificada e eficiente, surge o Programa de Restaurantes Populares, que embora instituído em 2004 por meio do Ministério do Desenvolvimento Social de Combate à Fome, a atuação dos mesmos no Brasil tem seu funcionamento datado desde a década de 1940, mas que regulado pelo Estado e por depender da liberação de recursos públicos apresentaram-se descontínuos e fragmentados (PADRÃO, 2018; VASCONCELOS, 2005).

O objetivo fundamental do Programa é o atendimento à população em estado de insegurança alimentar e a garantia de uma alimentação saudável e adequada a todos. Além das refeições servidas serem nutricionalmente balanceadas e atenderem as condições de higiene, o programa possui como parte dos objetivos específicos à promoção de ações de educação e hábitos alimentares saudáveis, a elevação da qualidade das refeições realizadas fora dos lares, o respeito a preservação da cultura alimentar local, a promoção da cidadania, o favorecimento da dignidade no ato de 
alimentar-se, entre outros (Brasil, 2004; CARRIJO, 2013). Mais do que um equipamento que oferece refeições baratas, se qualifica como uma estrutura multifuncional, atuando como motivador da emancipação social por meio do exercício de um direito humano e consolidação do controle social. (Brasil, 2010; OLIVEIRA, 2019).

Contudo, considerando o impacto que a atuação dos Restaurantes Populares exerce na sociedade, no pequeno número de equipamentos de mesmo caráter, nos bons resultados do programa quando ativo, e principalmente no cenário das desigualdades sociais, se faz necessária a presença de equipamentos como Restaurantes Populares nas cidades brasileiras, em especial na cidade de Presidente Prudente, a qual se localiza no interior do estado de São Paulo, região do Oeste Paulista, possuindo uma população estimada de 228.743 habitantes, segundo o senso do Instituto Brasileiro de Geografia e Estatística-IBGE (2019), onde espaço urbano apresenta uma estrutura espacial desigual (GONÇALVES; CAMPOS; DESARTI, 2011; OLIVEIRA, 2019).

$O$ estudo que se segue baseia-se em um estudo que buscou por um possível local para implantação do equipamento na cidade em questão, levando em conta as características da região, a população local, as formas de acesso e os possíveis impactos, de maneira que 0 equipamento possa mitigar os problemas da camada mais baixa e vulnerável socialmente, presente principalmente nas periferias da cidade. Ainda, antecedentes projetuais foram analisados e estudados para que o entendimento e o olhar acerca das características que regem um restaurante sejam evidenciadas, aprimorando o conhecimento quanto ao funcionamento e composição formal do mesmo, principalmente em relação a uma perspectiva mais popular, com o intuito que a compreensão dos resultados contribua para a elaboração e desenvolvimento do projeto.

\section{MÉTODOS}

A metodologia utilizada para o desenvolvimento do artigo baseou-se em uma pesquisa qualitativa, apoiando-se em levantamentos bibliográficos possibilitados através de consultas em fontes de dados secundários, como livros, dissertações, teses e conteúdos disponibilizados por meio digitais que possuem relação com a temática. Através das análises de correlatos, foi possível uma melhor compreensão de questões técnicas, funcionais e formais de edifícios que comercializam refeições.

Foram realizadas ainda visitas in loco, levantamentos, análises de uso e ocupação do solo, medições e registros fotográficos da área de estudo, de forma a apresentar o atual cenário e condições da pré-existência estudada e seu entorno, para então viabilizar o desenvolvimento das diretrizes projetuais dentro de limitação reais.

\section{RESULTADOS}

Para que se possa compreender a complexidade de um estabelecimento alimentício é necessário os estudo de correlatos, dessa forma, foram analisadas três obras, sendo um restaurante na Cidade do México, com as características que se voltam mais a um público selecionado, destinado aparentemente à classe média e alta, um restaurante fabril na cidade de Marília, destinado à classe operária, e um restaurante popular, em Curitiba, com o princípio da universalização mas que recebe principalmente os trabalhadores e uma classe predominantemente mais baixa socialmente.

O primeiro, o Restaurante Campobaja, foi projetado pelo Estúdio Atemporal em 2015, possuindo muita autenticidade em seus $224,00 \mathrm{~m}^{2}$ de área construída (FARIAS, 2019). Embora esteja localizado na cidade do México, a sensação quando se adentra o edifício é de estar na cidade de Ensenada, uma cidade litorânea ao noroeste do país. Dessa forma o conceito proposto pelos arquitetos foi claramente alcançado através de uma arquitetura sensorial, possibilitado principalmente pela decoração do local. 
Figura 1. Fachada do Restaurante Campobaja, na Cidade do México.

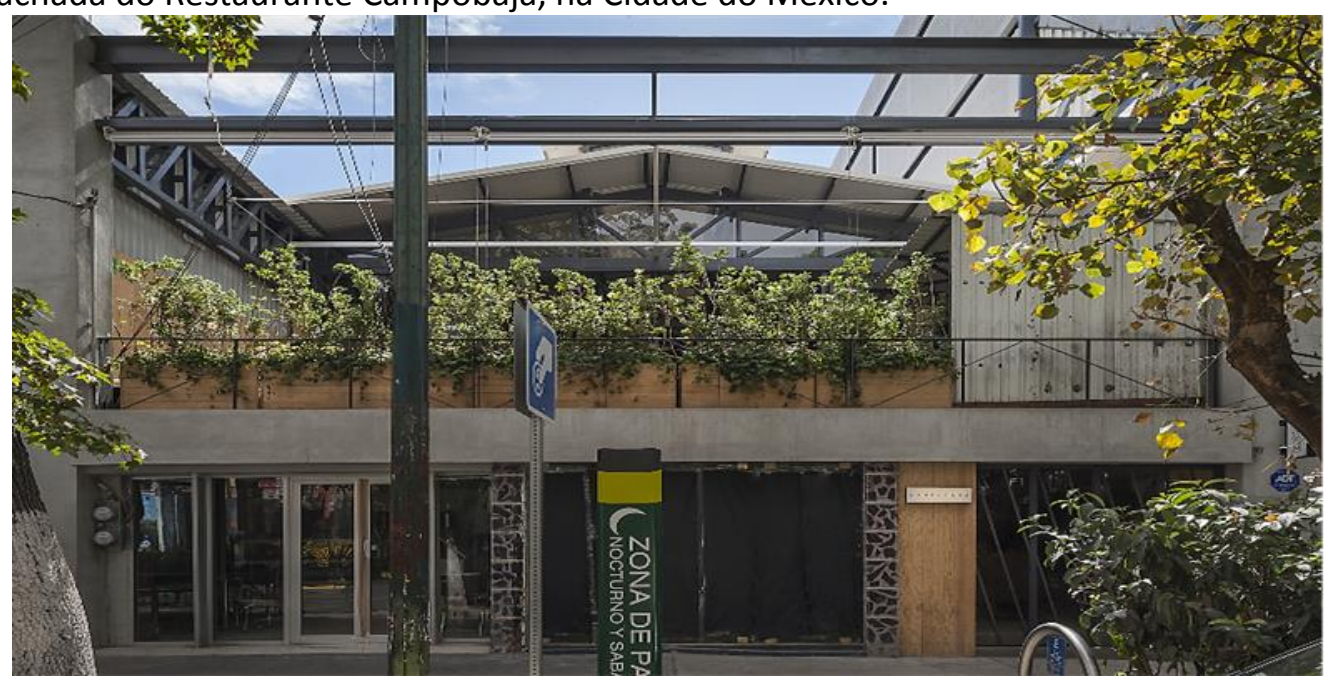

Fonte: Estúdio Atemporal (2019).

O programa se divide em dois pavimentos, onde o primeiro é composto por uma pequena área de recepção, a qual se apresenta através de uma planta livre e com decorações marítimas por todo canto, remetendo a cidade costeira. Através de uma escada em espiral se tem o acesso do segundo pavimento, composto, além das áreas de serviços, como a cozinha e o bar, por um grande salão e terraço descoberto, ambientes estes que são integrados através de uma grande abertura. Ao adentrar o local percebe-se que o pé direito aumenta dramaticamente, e a estrutura do telhado tornase a protagonista, sendo esta uma cobertura metálica duas águas e com lanternim, o qual, somado ao grande vão da porta, possibilitam a entrada de iluminação e ventilação natural. (DIVISARE, 2016; FARIAS, 2019).

Em relação aos fluxos, nota-se a flexibilidade e a livre circulação dos clientes, se estendendo desde a recepção, ao salão principal e terraço, ressaltando a integração entre os espaços. Referente a cozinha e o fluxo dos alimentos, pode-se dizer que se apresentam, aparentemente, linear e ordenado, evitando cruzamentos referentes aos processos de preparação.

Figura 2. Plantas baixas com indicação dos fluxos dos ambientes que compõe o Restaurante Campobaja.

$\nabla$ sem escala

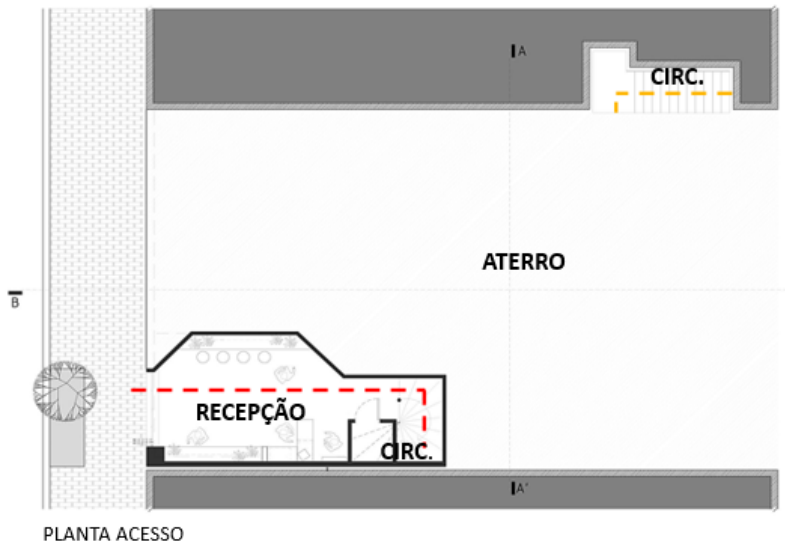

LEGENDA:

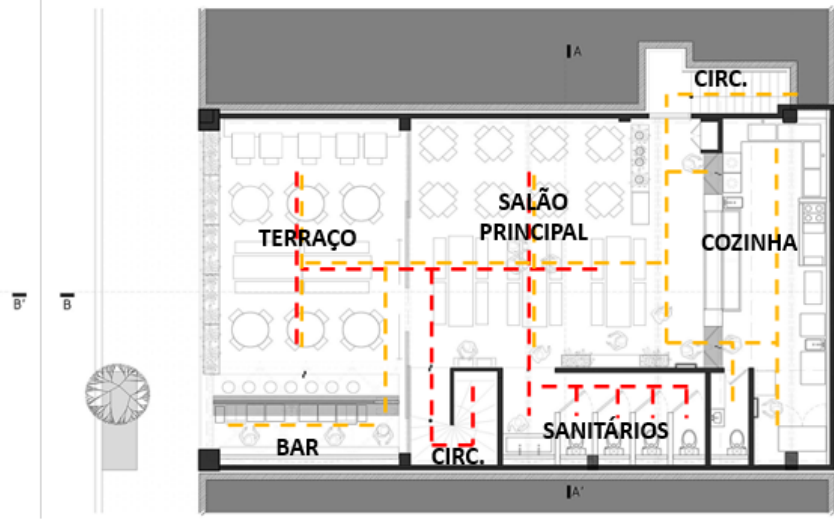

PLANTA RESTAURANTE

Fonte: Estúdio Atemporal (2019), modificado pela autora (2020). 
Quanto ao interior do edifício, nota-se que os materiais utilizados foram deixados para falar por si mesmo, sendo muito deles recuperados da cidade costeira e expostos em sua forma original, com o objetivo de proporcionar uma experiência única de transporte para outro local. Vale destacar a presença marcante de uma arquitetura voltada ao estilo industrial, presentes nas paredes revestidas em madeira, no piso de cimento queimado, nas esquadrias de ferro, nos blocos de concreto, na forma da cobertura e nos mobiliários rústicos.

Figura 3. Interior do edifício com elementos e decorações que remetem o estilo industrial.

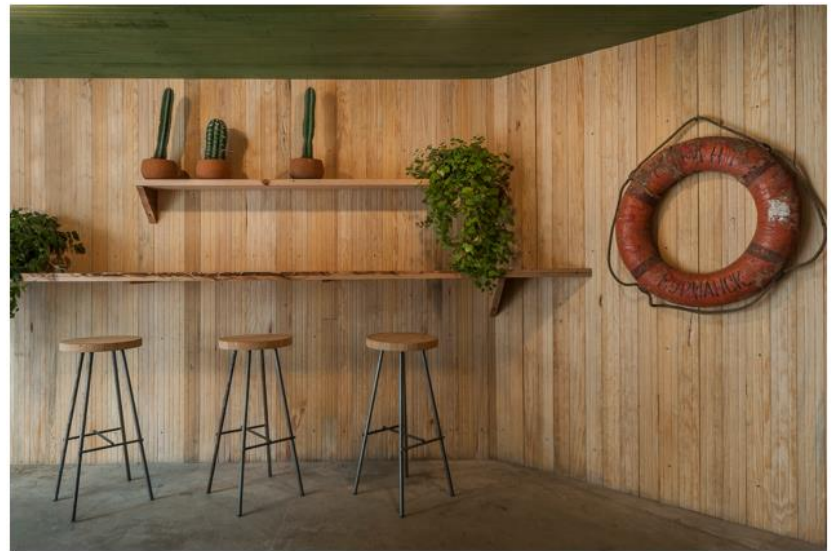

Fonte: Estúdio Atemporal (2019).

O segundo antecedente, localiza-se na cidade de Marilia, é um restaurante projetado pelo Grupo NPC para atender os 2000 funcionários da fábrica Marilan, este, se insere com naturalidade em meio aos demais blocos que compõe a fábrica, através da manutenção de

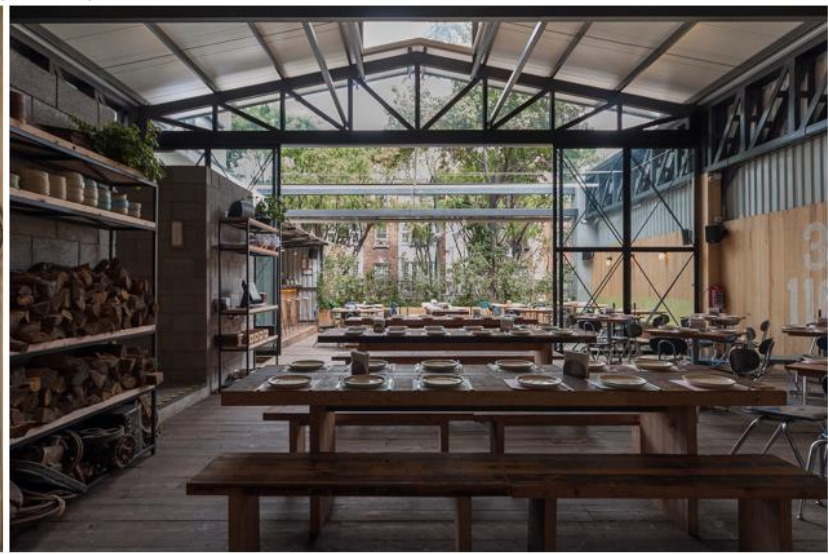

uma linguagem pavilhonar que se apresenta por meio de uma arquitetura singular e contemporânea, possuindo soluções que introduzem os aspectos de conforto térmico, imagem empresarial, e bem estar dos usuários (ARCOWEB, 2008).

Figura 4. Fachada do Restaurante Fabril da Marilan.

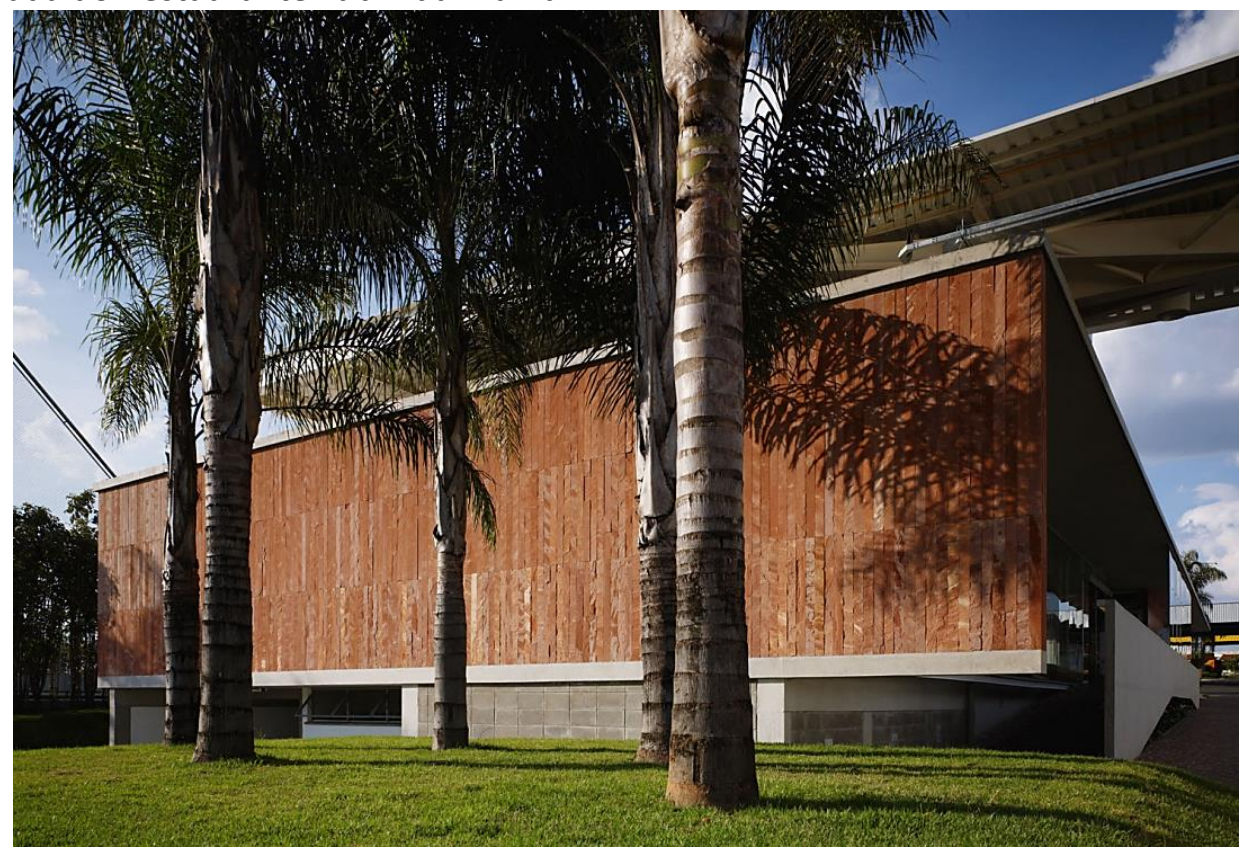

Fonte: Nelson kon (2008). 
$O$ restaurante se edifica em um volume horizontal, posicionado em um lote em declive que foi aproveitado pelos arquitetos para criação de um nível inferior de serviço na lateral sul. 0 programa de necessidades conta ainda, com uma cozinha industrial e um grande refeitório, e toda a disposição dos espaços priorizam a funcionalidade, configurando uma hierarquização linear tanto em relação aos processos de preparação dos alimentos, quanto higienização do público, demonstrando uma organização efetiva e higiênica (ARCOWEB, 2008).

Figura 5. Planta baixa com indicação dos fluxos dos ambientes que compõe o Restaurante Fabril da Marilan.

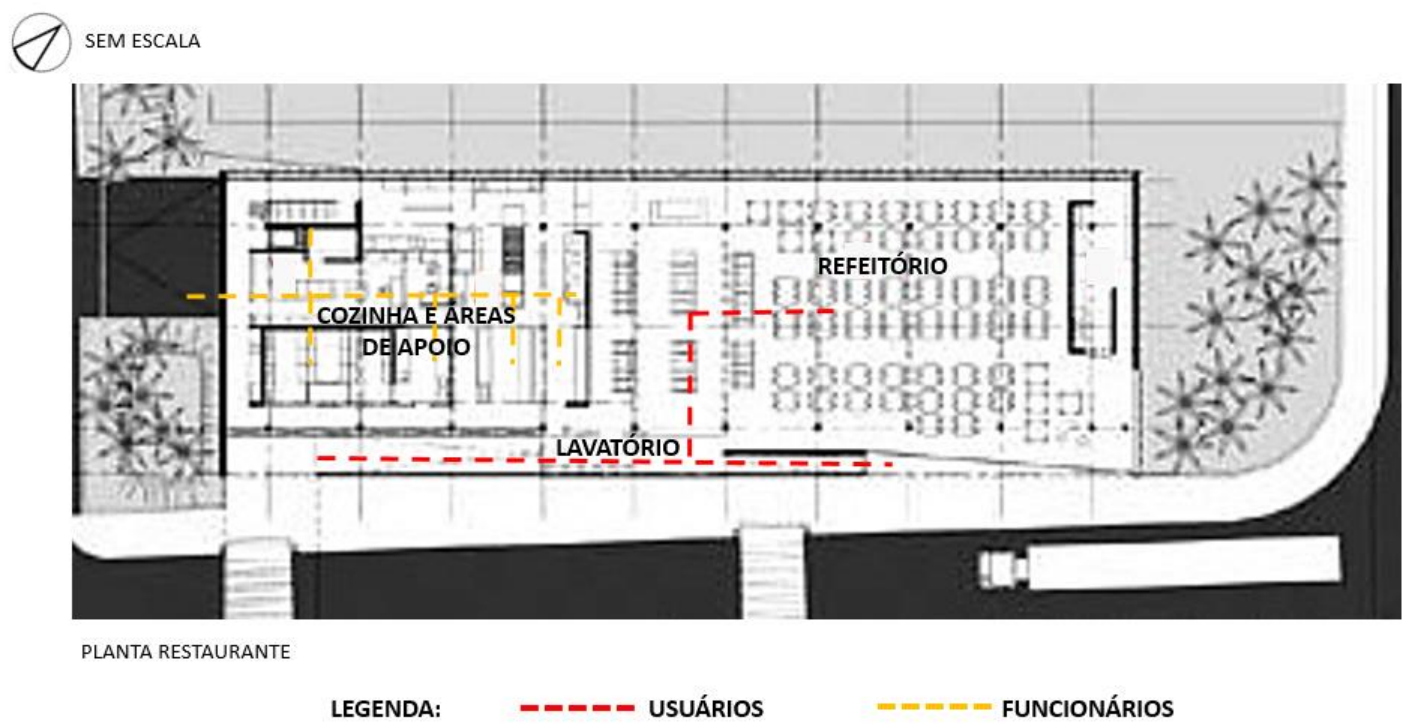

Fonte: Arcoweb (2008), modificado pela autora (2020).

Em questão da materialidade, o projeto é composto predominantemente por concreto e aço, vale ressaltar que o clima predominantemente quente da região, bem como a implantação, fora motivador para a escolha do tipo das vedações. Para isso, foram utilizados elementos cerâmicos vazados para a face que se volta para o oeste, tal escolha se justifica pela capacidade que os blocos possuem de filtrar a incidência solar e a garantia máxima ventilação. As laterais, foram revestidas com o arenito paraná-vermelho, o qual possui tonalidade que se assemelha bastante a dos blocos, enquanto a face frontal, recebeu grandes panos de vidro, inclusive na parte da cozinha, permitindo o acompanhamento do preparo do alimento. (ARCOWEB, 2008).

A permeabilidade visual, intencionada no projeto, cria um ambiente confortável ao ato da alimentação, promovendo a interação entre o meio interno e o exterior do edifício, resultando em uma maior dinamicidade e descontração do espaço. Pode-se dizer também que a interação entre os meios não se limita a permeabilidade visual, mas ocorre ainda por meio da entrada de diferentes níveis de luminosidade e brisa ao interior do restaurante, advindas de diferentes sentidos correspondentes às épocas do ano. 
Figura 6. Materialidade das vedações escolhidas.
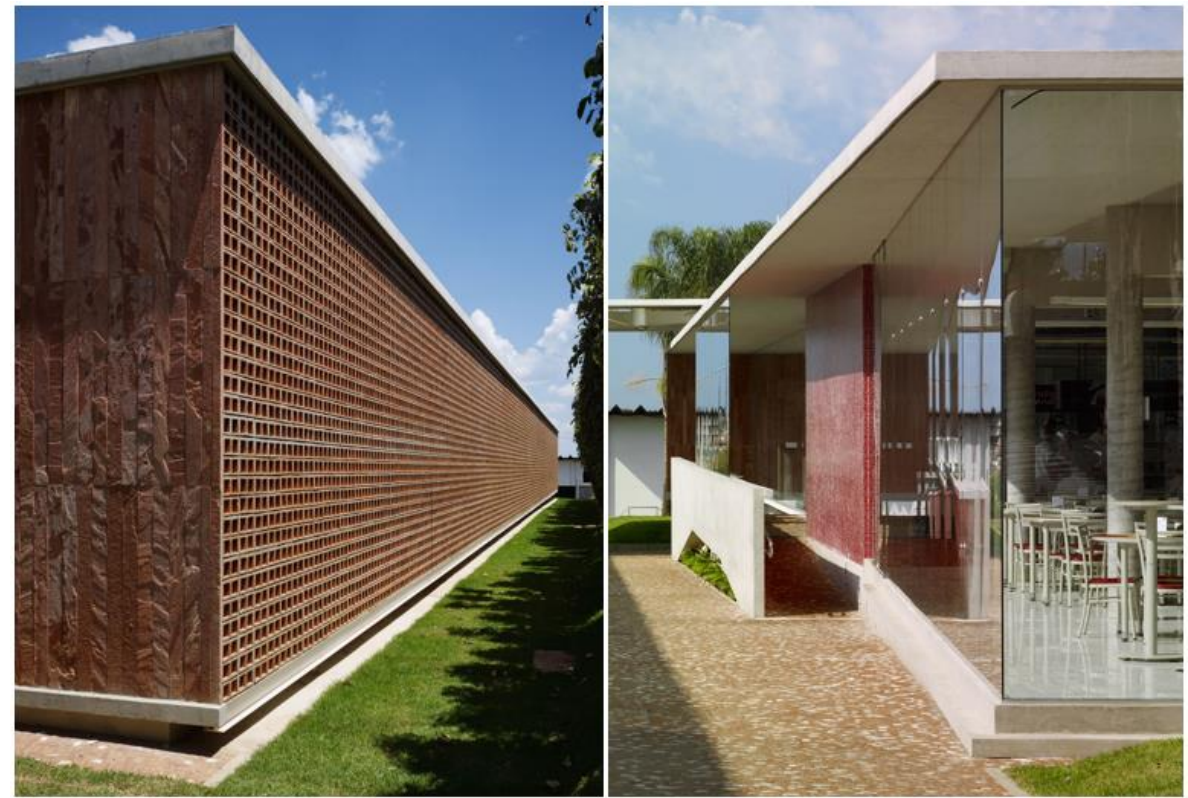

Fonte: Nelson kon (2008).

O terceiro e último antecedente se volta a um restaurante de vertente mais social. É o Restaurante Popular do Capanema, localizado em Curitiba sob as estruturas de um Viaduto. O projeto foi de responsabilidade do Instituto de
Pesquisa e Planejamento Urbano de Curitiba, o qual teve como desafio revitalizar um edifício que estava abandonado há mais de 18 anos. (PREFEITURA DE CURITIBA, 2017).

Figura 7. Fachada do Restaurante Popular do Capanema.

Fonte: Prefeitura de Curitiba (2018)

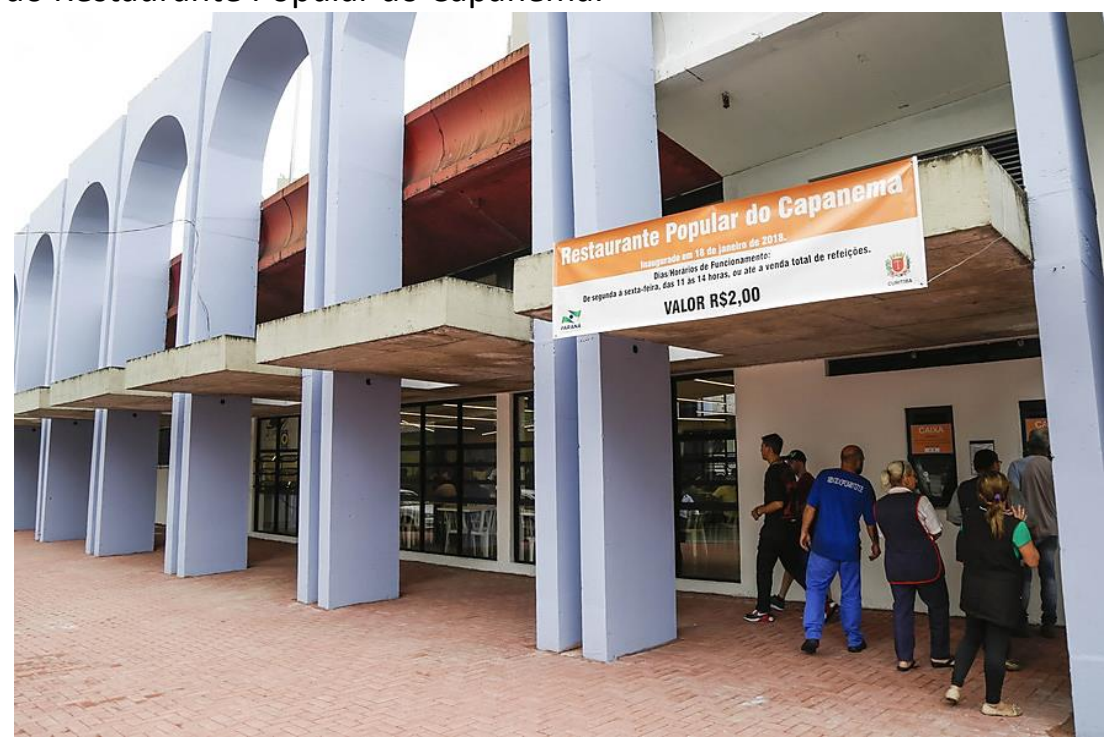

O programa conta com uma grande praça de alimentação, equipada com mesas, banheiros, lavatórios, salas de apoio, e não havendo cozinha, o programa conta com áreas de circulação independentes onde ocorre a manipulação e inspeção dos alimentos por um nutricionista, pois os mesmos não são preparados no local, mas em outra unidade de restaurante popular e transportada pronta até lá, isso pois precisam atender as normas da Vigilância Sanitária. Conta ainda com área de recepção e distribuição dos alimentos, área de higienização de utensílios, e vestiários, estes, possuem acesso restrito aos profissionais da Secretaria Municipal da Agricultura e Abastecimento. (IPPUC, 2017). Também, referente ao programa de 
necessidades, um posto de atendimento da Fundação de Ação Social para atendimento da população.

O fluxo foi pensado do início ao fim para que o restaurante funcione de acordo de uma lógica onde o usuário tenha acesso aos lavatórios logo na estrada, siga onde ocorra a distribuição das refeições, acesse as mesas, e por fim, deposite o prato na saída para que seja higienizado. $O$ mesmo em relação ao recebimento do alimento e saída do lixo.

Figura 8. Planta baixa com indicação dos fluxos dos ambientes que compõe o Restaurante Fabril da Marilan.

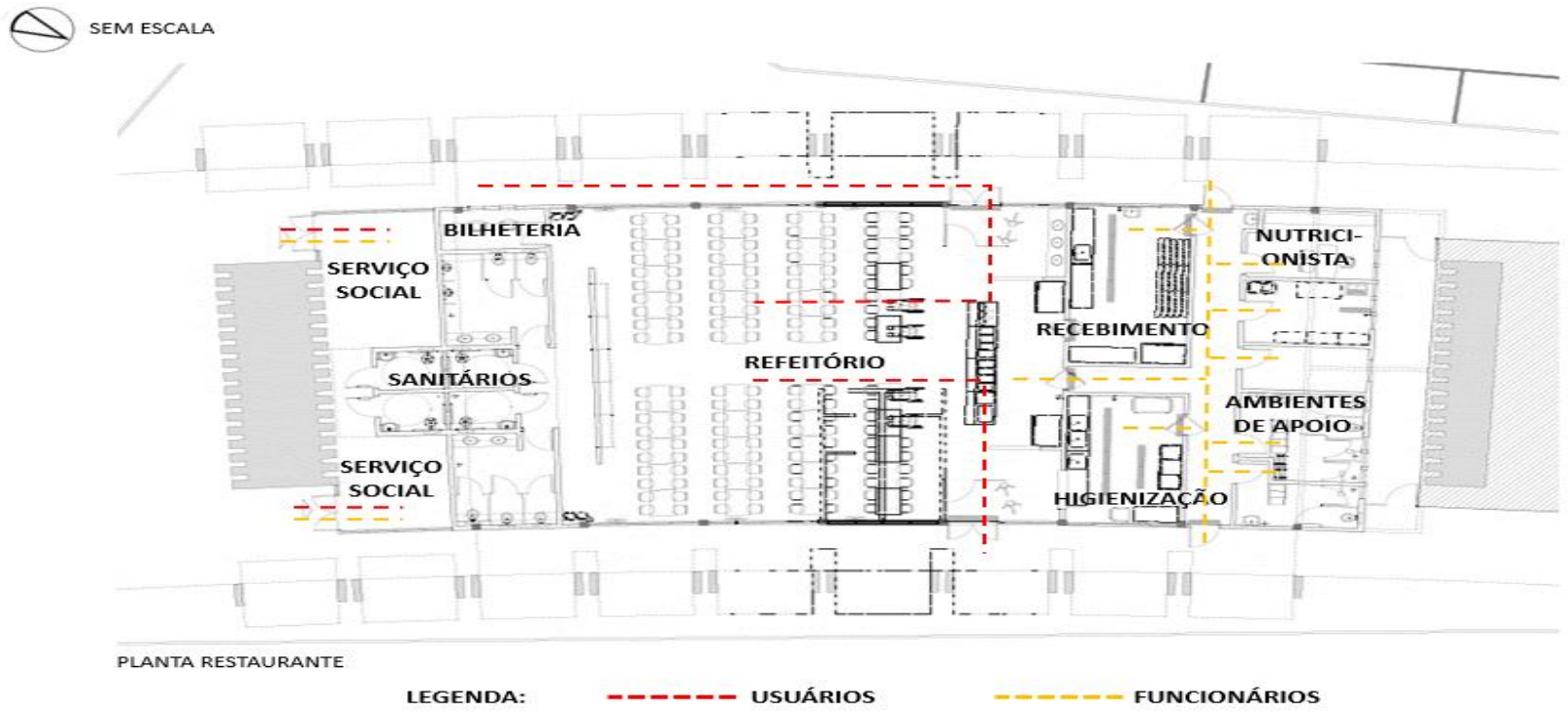

Fonte: IPPUC (2017), editado pela autora (2020).

Sabendo que se trata de um restaurante que se volta para uma vertente mais social, percebe-se que a arquitetura projetada para ele foi pensada de forma que se ajustasse à todas as realidades humanas, despertando sensação de pertencimento principalmente à um grupo mais vulnerável socialmente. De acordo com Bortolin e Gomes (2017), o pertencimento induz as relações sociais e a relação do sujeito na sociedade, e com base em uma arquitetura inclusiva ocorre a relação de vínculo do usuário com o espaço, que serve como base para convivência em grupo. Nota-se a responsabilidade social quando nos deparamos com os espaços totalmente comprometidos com o usuário, o que vai desde a escolha do mobiliário à humanização através de um painel colorido aos fundos do restaurante.

Figura 9. Fotografia do restaurante em funcionamento.
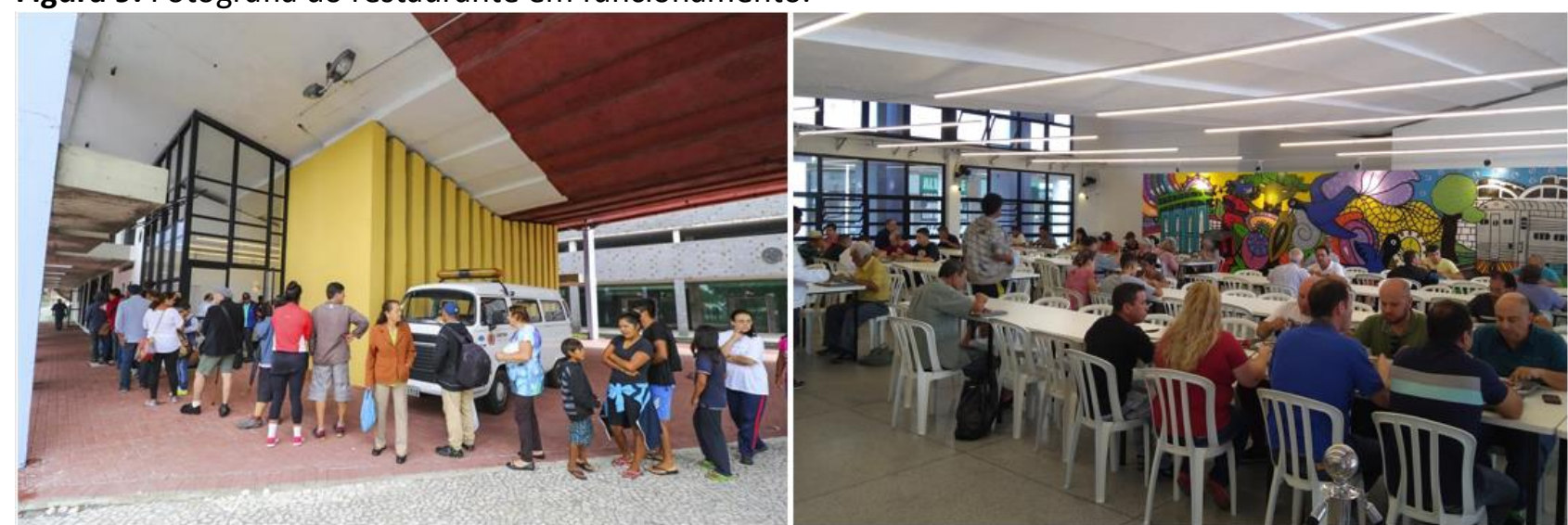

Fonte: Prefeitura de Curitiba (2018). 
Embora saibamos que os restaurantes, assim como qualquer outra tipologia de construção, possuem regras e normativas a serem seguidas, ao se analisar as referências projetuais com ênfase nos detalhes construtivos e resultados pós ocupação, passamos a ter um olhar mais sensível capaz de reconhecer questões de tamanha importância, como a intenção de criar uma arquitetura que estimule as boas sensações dos usuários, como acontece no Restaurante Campobaja, o valor de pensar no conforto térmico e bem estar na hora de se alimentar, potencializado pelas escolhas das vedações no Restaurante Fabril da Marilan, ou então, na simplicidade de um estabelecimento de vertente social, motivando o pertencimento do usuário com o local, como exposto no Restaurante Popular do Capanema.

Todas essas questões, sejam elas funcionais ou estéticas, influenciam na decisão pessoal em frequentar ou não determinado local, sabendo que são vários os motivos que levam uma pessoa a procurar um restaurante, se precipita quem imagina que seja só pela alimentação, existem outras razões que podem estar associadas ao status, a peculiaridade do ambiente referente à decoração, a relação com os funcionários, o clima interno e conforto, a questão do preço, a presença de um cardápio elaborado, por curiosidade a partir de indicações de amigos ou mídia, quanto ao estilo de serviço diferenciado ou ainda em relação ao Chef desenvolver um bom trabalho (VENTURI, 2003).

Dito isso, as características do espaço físico, como a escolha do mobiliário, a decoração ou então o funcionamento, aguçam os sentidos dos usuários envolvendo-os emocionalmente e, portanto, a arquitetura de cada estabelecimento precisa estar intimamente ligada ao público destinado, criando espaços que se ajustem ao público alvo.

Todas as decisões projetuais tomadas para o restaurante, seja o dimensionamento dos espaços, as cores escolhidas, o design do mobiliário, o tipo e o efeito de iluminação utilizados, os materiais e texturas, causam impactos positivos ou negativos nos seus usuários influenciando a escolha ou não, do local, caracterizando assim o fator psicológico. (SOUZA, 2011, p. 10).

Assim, quando se pensa em um restaurante de cunho social, como é o caso dos restaurantes populares, precisa- se entender que a composição do espaço físico deve servir como objeto que desenvolva ambientes responsáveis que despertem a sensação de pertencimento e acolhimento aos usuários, e para que dessa forma, a função a qual foi destinada o edifício possa seja concretizada com satisfação.

\section{DISCUSSÃO}

A fim de que a proposta do Restaurante Popular para a cidade de Presidente Prudente seja pautada em limitações reais, se faz necessário 0 atendimento das especificações técnicas e recomendações regidas pelo Ministério do Desenvolvimento Social do Combate à Fome (MDS). Dentre as diversas normatizações expostas em documentos, há aquelas que ditam sobre o local ideal para a implantação do equipamento, a funcionalidade, os dimensionamentos, os ambientes essenciais, as questões de higiene e salubridade, entre outras.

Aliada a elas, com base nos estudos realizados e apresentados dos três antecedentes projetuais, onde é possível perceber as questões de pós ocupação dos espaços, e ainda com fundamento nas áreas de conhecimento aprendidas durante a graduação do curso de Arquitetura e Urbanismo, foram definidas as diretrizes para o projeto, estas, que são de grande valia e fundamentais para que o edifício cumpra sua função social no meio urbano.

A primeira delas refere-se à localidade do equipamento, a qual, de acordo com as recomendações do MDS, deve ser escolhida por meio da busca de um local que concentre possíveis usuários, que se caracterize pela aglomeração e grande fluxo dos mesmos, considerando a universalização do Programa dos Restaurantes Populares e o fácil acesso da camada mais baixa e vulnerável socialmente.

Quanto a isso pode-se dizer que em relação a malha urbana da cidade são inúmeras as áreas que podem ser consideradas como possíveis lugares para a implantação do equipamento, visto os índices de exclusão social que estão presentes em áreas dispersas na 
cidade, principalmente nas periferias. Entretanto, considerando que ao escolher um determinado bairro $o$ atendimento se torna especifico a ele, foi definida uma localização central, levando em conta a possibilidade de acesso do segmento social de menor flexibilidade de deslocamento.

Dessa forma, a localização tida como ideal é uma pré-existência na região central da cidade, uma vez que as chances de se encontrar espaços vazios na área urbana que esteja de acordo com a proposta do projeto referente à localização são escassas. Sobre ela, considera-se uma maior facilidade de convergência de qualquer fluxo vindo dos bairros, em contraposição à seleção pontual próximo às extremidades da malha urbana. Acrescenta-se a facilidade de acesso, o grande conhecimento do local de implantação, levando em conta que a área central concentra espaços de comércio, serviço e institucionais que geram um grande fluxo de pedestres durante todo o dia, por possibilitarem a realização de diversas atividades bem como o suprimento das necessidades e desejos da população, se destacando como um espaço de consumo.

Figura 10. Localização escolhida em relação a malha urbana da cidade de Presidente Prudente.

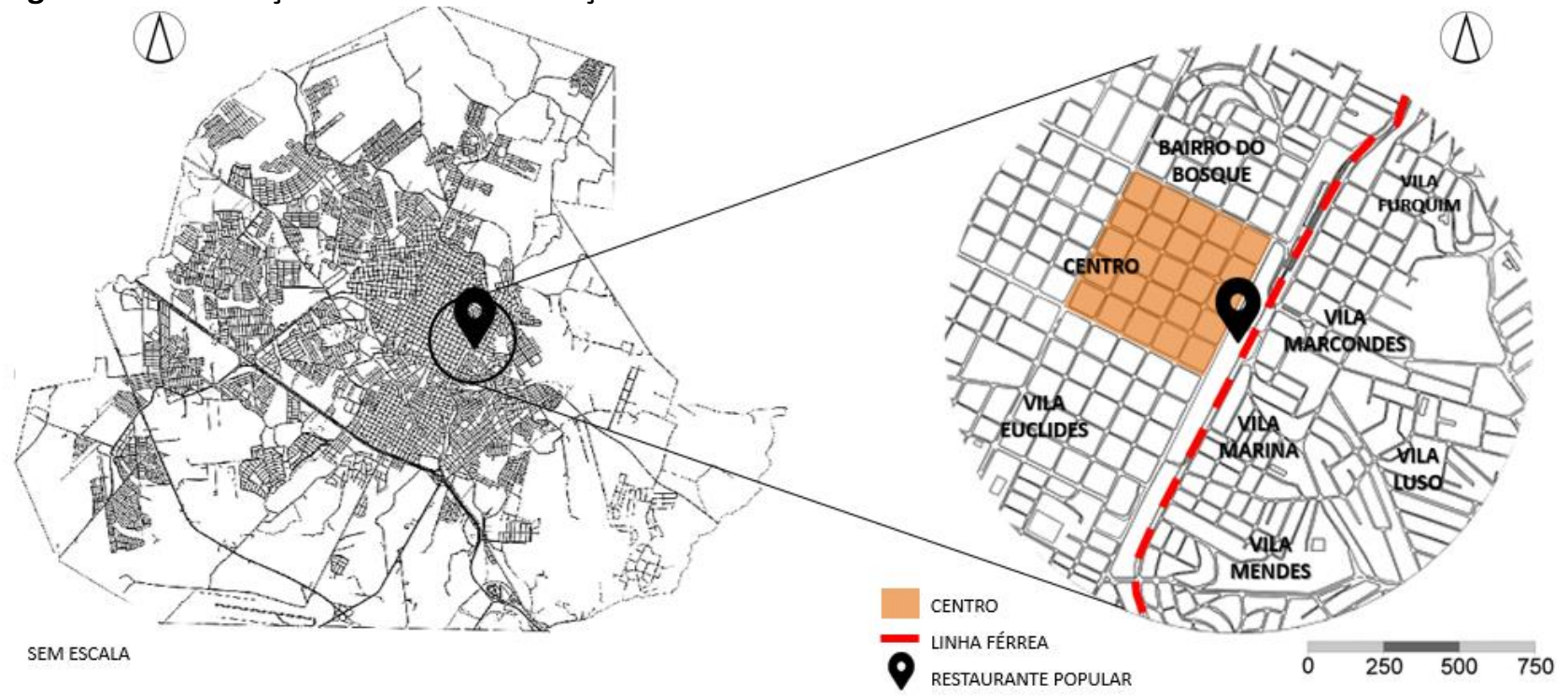

Fonte: A autora (2020).

Compreendendo o calçadão, o camelódromo, e a igreja Nossa Senhora da Aparecida, foi possível avaliar por meio de visitas in loco que parcela da população central é excluída socioeconomicamente e evidenciam suas necessidades e misérias por meio do próprio corpo, o que se nota eventualmente nas calçadas, como exemplo os moradores de rua, pessoas vendedoras de arte, desempregados, ciganos, ambulantes, entre outros, necessitando assim de uma alimentação à um valor acessível.

Dito isso, é importante considerar também as características do próprio lote, mais especificamente a pré-existência, a qual possui uma edificação que atende bem a um programa de necessidades amplo, possuindo as dimensões adequadas para receber uma grande demanda de usuários e infraestrutura básica. Possuindo $1716,50 \mathrm{~m}^{2}$ de área total, o lote possui a fachada principal voltada para a Rua Barão do Rio Branco, via coletora da cidade, e se caracteriza atualmente por possuir mais de uma função, sendo um estacionamento privado a qual ocupa a maior metragem quadrada. Além deste uso, há a presença de lojas, de um estacionamento posterior, e um prédio residencial, este, que possui o térreo predominantemente livre, de uso comercial, e com os pavimentos superiores concentrando os apartamentos. 
Figura 11. Fachada principal da pré-existência escolhida para implantação do Restaurante Popular.

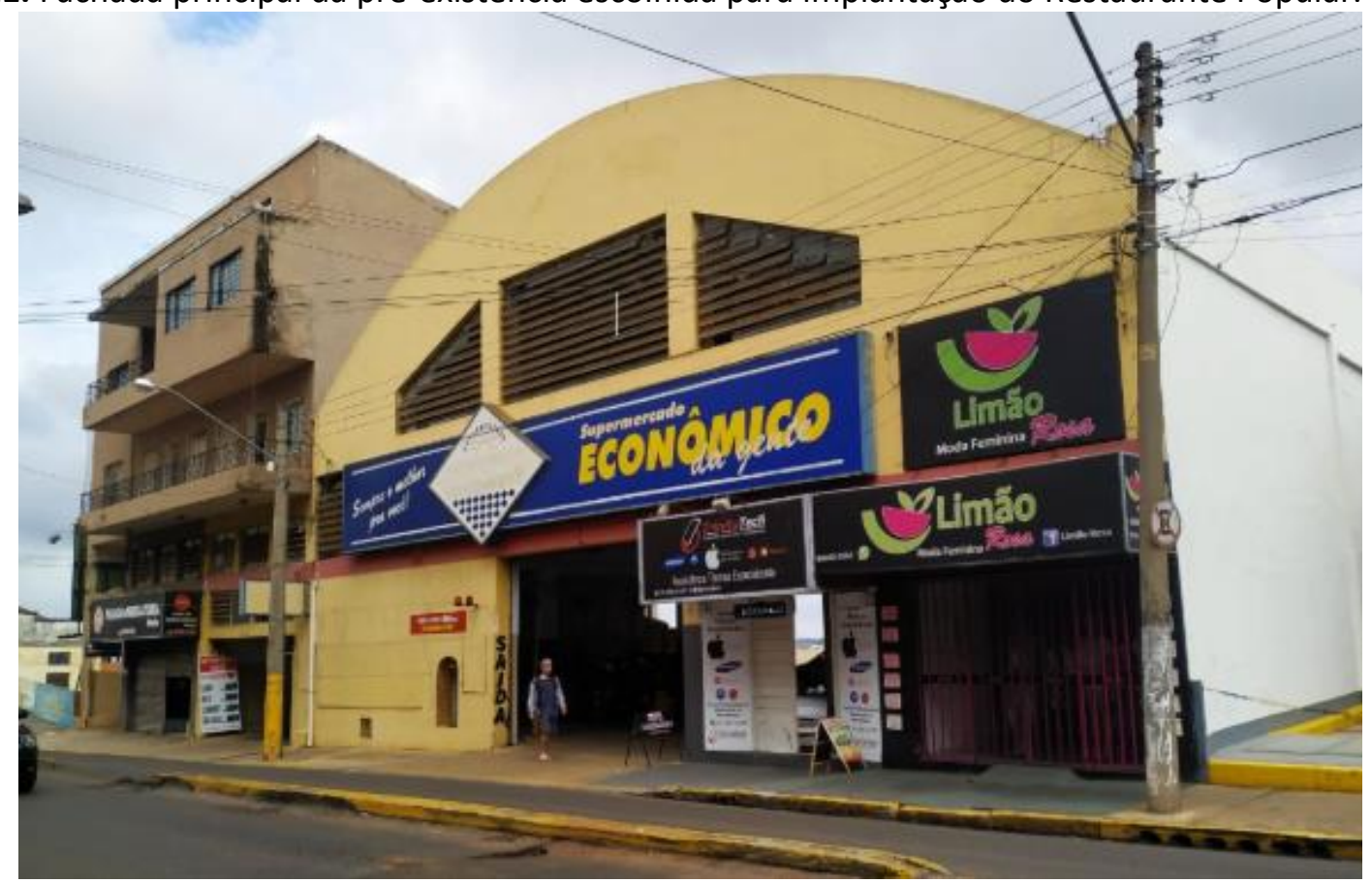

Fonte: Arquivo pessoal (2020).

A fim de transforma-la em um Restaurante Popular, o qual se volta a uma tipologia de construção mais popular, é necessária tomar uma série de decisões quanto ao conceito do edifício e arquitetura propriamente dita, entre elas, a criação de um espaço de caráter público, universal e democrático, onde através de sua própria essência permita a conexão de diferentes pessoas, de diferentes raças, crenças e etnias, em diferentes horários do dia. Através do espaço, a ideia é de que seja transmitido um impacto positivo de aproximação do público, onde além da garantia de um ambiente funcional e bem aproveitado, que o foco ao se projetar sejam as experiências das pessoas que possam usufruir do restaurante, de forma a criar uma relação com o próprio edifício.

Com isso, a arquitetura deve possibilitar ao usuário, antes de tudo, a sensação de pertencimento ao local, de forma que ao realizar as refeições o mesmo se sinta incluso e confortável. Para tanto, é idealizada um ambiente que faz referência ao estilo industrial, bem como se apresenta o Restaurante Campobaja, sendo este estilo caracterizado por possuir personalidade ao mesmo tempo em que se apresenta de forma simples, possuindo elementos como cimento queimado nos pisos e paredes, revestimento de tijolos a vista, uso de cores neutras, grandes vãos, integração entre ambientes, entre outras.

A estrutura original contribui para a composição do design industrial, haja vista a cobertura existente do volume principal. Ainda, tratando-se de uma reforma, questões de tubulações e fiações expostas, dispensa de forros e demãos de tintas, refletem na economia, aspecto positivo ao saber que a construção do restaurante depende da liberação da verba pública. O objetivo é a criação de um ambiente cru, o mais simples possível, mas ao mesmo tempo aconchegante. Texturas como concreto, madeira, e tijolos serão valorizados, bem como nuances de preto, cinza e marrom. O mobiliário e os elementos paisagísticos contribuem diretamente para a composição do ambiente, possuindo fundamental importância, assim como fora apresentado nos resultados, se tratando do antecedente da Cidade do México.

Dessa forma, o projeto arquitetônico e de interiores devem se integrar para a produção de uma arquitetura convidativa, por não se contentar apenas em um ambiente agradável, por mais que este responda aos padrões técnicos e estéticos, mas que seja oferecido o bem-estar e garantida a satisfações dos usuários, sendo estes potencializados pelo conforto térmico e paisagismo de contemplação. Assim, os recuos surgem de forma a desfocar a linha entre o público e o privado, estendendo a função do 
edifício além de suas paredes e fazendo com que este se torne um espaço de socialização e convivência em qualquer horário do dia, além disso, funcionam também como uma estratégia para minimizar possíveis problemas referente à casos de aglomerações em frente ao edifício nos horários de funcionamento do mesmo.

Figura 12. Estudo da volumetria com recuos da fachada.
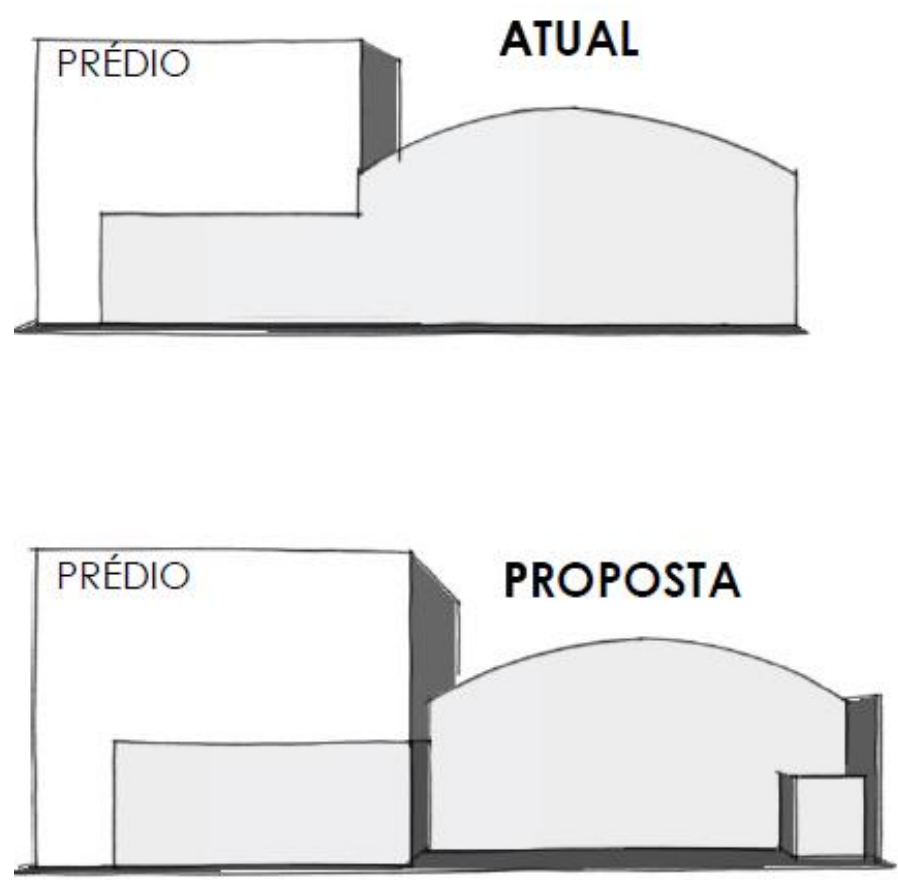

Fonte: A autora (2020).

Ainda, enquanto diretriz, à humanização do espaço, tendendo a possibilitar as relações de convivência e trazendo dessa forma no projeto a concepção de valores sociais e culturais. Também, o respeito às características do entorno, da cidade, e principalmente do próprio edifício, procurando evitar, minimizar ou compensar qualquer impacto negativo que 0 empreendimento possa vir causar no meio no qual se insere, além de se apropriar positivamente das condicionantes do terreno, usando-as de forma favorável na concepção do projeto.

Além disso, a presença de soluções que buscam resolver as questões de conforto térmico, criando um clima arejado e agradável, seja através da ventilação natural aprimorado pelas grandes aberturas ou por meio da iluminação controlada conforme incidência solar, ora permitindo a entrada de luz, ora evitando, tendendo dessa maneira fechamentos na fachada norte e aberturas ao sul e leste, sabendo que o vento predominante da região parte desta orientação. Assim como no Restaurante Fabril da Marilan, as escolhas das vedações devem somar ao projeto potencializando o melhor aproveitamento das condições climáticas, seja por meio do uso de elementos vazados ou através de materiais com boa capacidade para filtrar a incidência solar, sabendo que a cidade de Presidente Prudente possui o clima quente.

Ainda, referente ao conforto dos usuários, a presença de paisagismo, tanto na fachada como no interior do edifício, apresentado com a aparência mais natural possível, resgatando a beleza da vegetação nativa e sobretudo harmonizando com a arquitetura.

Quanto aos ambientes, $\mathrm{o}$ respeito e atendimento ao programa de necessidades exposto no roteiro de implantação do MDS, e a adição de ambientes que possam contribuir com a tipologia, como salas destinadas aos profissionais do Serviço Social para o atendimento da população e a presença de lavatórios logo no hall de entrada, estimulando a higiene pessoal como pré-requisito a alimentação, assim como acontece no Restaurante Popular do Capanema, em Curitiba. o fluxo deve ser ordenado e contínuo, evitado o cruzamento de atividades, e os ambientes 
setorizados de forma coerente, seguindo as restrições e recomendações estabelecidas em documentos vinculados ao Programa de Restaurantes Populares. Além do mais, questões como dimensionamentos, materialidade, temperatura, entre outras particularidades também devem ser respeitadas, bem como as considerações que se relacionam ao controle higiênico sanitário.

Somada a todas as diretrizes já mencionadas, a intenção de que o Restaurante Popular seja entendido além de um espaço coletivo e acessível a todos, mas que acima de tudo, seja compreendido principalmente como um espaço político, garantindo aos usuários a experiência da emancipação social por meio da obtenção do direito à alimentação saudável em um local adequado.

Por fim, ao se tratar de um espaço de representação social, movidos pelas relações de afetividades com o lugar, como as sensações emotivas de segurança e proteção, e sabendo que os lugares só adquirem significado por meio das intenções humanas, do espaço físico e das atividades desenvolvidas, surgem as questões de ambientes que promovam o contato entre pessoas e entre o meio como parte do programa de necessidades, garantindo um ambiente mais interessante e dinâmico. Com isso, áreas de convivência com 0 apoio de mobiliários compostos por materiais de leitura informativa ou literária. Ainda, ligada à linha cultural, a inserção de um palco pouco elevado onde durante o funcionamento do restaurante possa ocorrer apresentações de músicas ou diversas outras manifestações artísticas, potencializando o uso do equipamento.

Contudo, por meio das diretrizes projetuais apresentadas, e sabendo das vantagens sociais e econômicas que o equipamento oferece, a implantação do mesmo na cidade de Presidente Prudente viria, como uma ação social justificada e eficiente, para o combate da fome e diminuição das desigualdades, atendendo aqueles que historicamente foram abandonados pelo poder público e que carecem de atenção, de cuidados e principalmente de alimentação, colocando a dignidade humana em primeiro lugar. Além de beneficiar o desenvolvimento da sociedade em diferentes aspectos, se caracteriza como uma estrutura universal, incluindo a todos socialmente e procurando mitigar os problemas que atingem a parcela mais vulnerável da população, que afligem todas as idades e interfere no desenvolvimento do ser humano.

Como ação do Estado, é fundamental a implantação de políticas públicas funcionais, como é o caso do Restaurante Popular, e como ação da sociedade, devemos nos atentar as questões do combate à fome e nos questionar sobre a real responsabilidade que cabe a cada um pela continuidade da deplorável realidade que vivemos, em convivermos com pessoas que padecem de fome e ainda assim insistimos em fechar os olhos para elas, embora estejam ao nosso redor, dispersas por diversos cantos de nossa cidade, presentes em Presidente Prudente.

\section{AGRADECIMENTOS}

Agradeço a minha professora e orientadora Korina Aparecida Teixeira Ferreira da Costa, por todo auxilio, apoio e incentivo.

\section{REFERÊNCIAS}

ARCOWEB. NPC Grupo Arquitetura: Restaurante Fabril, Marília, SP. 2008. Disponível em: https://revistaprojeto.com.br/acervo/npc-grupoarquitetura-restaurante-fabril-15-04-2008/.

Acesso em: 20 abr. 2020.

BRASIL. Ministério do Desenvolvimento Social e Combate à Fome. Desenvolvimento Social e Combate a Fome no Brasil: Balanço e desafios. Brasília: MDS, 2010. Disponível em: https://aplicacoes.mds.gov.br/sagirmps/ferrame ntas/docs/24.pdf. Acesso em: 17 fev. 2020.

BRASIL. Ministério do Desenvolvimento Social e Combate à Fome. Manual Programa Restaurante Popular. Brasília: MDS, 2004. Disponível em: http://bvsms.saude.gov.br/bvs/publicacoes/proje to_logico_restaurante_popular.pdf. Acesso em: 29 fev. 2020.

BELIK, W., GROSSI, M. D. O programa fome zero no contexto das políticas sociais no Brasil. In: CONGRESSO BRASILEIRO DE ECONOMIA E SOCIOLOGIA RURAL, 41, 2003, Juiz de Fora. Anais [...]. Juiz de Fora: UFMG, 2003.

BORTOLIN, S.; GOMES, S. H. Ambientes de informação e o pertencimento. In: VII SECIN. SEMINÁRIO EM CIÊNCIA DA INFORMAÇÃO. 7., 2017. Londrina. Anais eletrônicos [...]. Londrina: UEL, 2017. Disponível em: http://www.uel.br/eventos/cinf/index.php/secin 
2017/secin2107/paper/viewFile/439/272. Acesso em: 16 abr. 2020.

CARRIJO, A. P. Avaliação do consumo alimentar nos Restaurantes Populares do Brasil. 2013. $97 \mathrm{f}$. Dissertação (Mestrado em Nutrição Humana) Universidade de Brasília, Brasília/DF, 2013.

DIVISARE. Estudio Atemporal Campobaja. 2016. Disponível em: https://divisare.com/projects/316549-estudioatemporal-luis-gallardo-lgm-studio-campobaja. Acesso em: 20 abr. 2020.

ESTÚDIO ATEMPORAL. Campobaja. 2019. Disponível em: https://estudioatemporal.com/portfolio/campob aja/. Acesso em: 12 maio 2020.

FARIAS, A. S. Estudo de Caso: Arquitetura e Urbanismo, 2019. Disponível em: https://www.docsity.com/pt/. Acesso em: 23 abr. 2020.

GONÇALVES, M. P; CAMPOS, S. T; DESARTI, F. M. Políticas públicas de segurança alimentar no Brasil: Uma análise do Programa de Restaurantes Populares. Revista Gestão \& Políticas Públicas. São Paulo: [s.n.], 2011. Disponível em: http://www.revistas.usp.br/rgpp/article/view/97 826. Acesso em: 12 mar. 2020.

IBGE. Instituto Brasileiro de Geografia e Estatística. Diretoria de Pesquisas, Coordenação de População e Indicadores Sociais. Estimativas da população residente. 2019. Disponível em: https://cidades.ibge.gov.br/brasil/sp/presidenteprudente/panorama . Acesso em: 04 maio 2020.

IPPUC. INSTITUTO DE PESQUISA E PLANEJAMENTO URBANO DE CURITIBA. Restaurante popular do Capanema é reaberto. 2017. Disponível em: http://www.ippuc.org.br/mostrarPagina.php?pag ina $=510$. Acesso em: 06 mar. 2020.

MOTA, R. S. O combate à fome e à pobreza na política externa brasileira (2003-2010): do discurso à prática e a prática do discurso. 2015. 161 f. Dissertação (Mestrado em Relações Internacionais) - Universidade de Brasília, Brasília/DF, 2015.
NELSON KON. Restaurante Indústria Marilan, NPC Arquitetura - Marília/SP. 2008. Disponível em: http://www.nelsonkon.com.br/restauranteindustria-marilan/. Acesso em 12 maio 2020.

OLIVEIRA, J. T. C. et al. Restaurantes subsidiados pelo governo como promotores da realização do direito humano à alimentação adequada: proposta de um modelo de avaliação. Revista Nutrição, Campinas, v. 32, e180193, 2019. Disponível em: http://www.scielo.br/scielo.php?script=sci_arttex $\mathrm{t} \& \mathrm{pid}=\mathrm{S} 1415$

$52732019000100521 \& \operatorname{lng}=e n \& n r m=i s o$. Acesso em: 03 maio 2020.

PADRÃO, S. M; AGUIAR, O. B. Restaurante popular: a política social em questão. Physis, Rio de Janeiro, v. 28, n. 3, e280319, 2018. Disponível em: http://www.scielo.br/scielo.php?script=sci_arttex $\mathrm{t} \& \mathrm{pid}=\mathrm{S0103}$

$73312018000300614 \& \operatorname{lng}=p t \& n r m=i s o . \quad$ Acesso em: 03 abr. 2020. DOI https://doi.org/10.1590/s0103-

73312018280319.

PINHEIRO, A. R. O; CARVALHO, M. F. C. C. Transformando o problema da fome em questão alimentar e nutricional: uma crônica desigualdade social. Ciência \& Saúde Coletiva [online] v. 15, n. 1, p. 121-130, 2010. Disponível em:

https://www.scielosp.org/article/csc/2010.v15n1 /121-130/\#ModalArticles. Acesso em: 30 de jul. de 2020. DOI: https://doi.org/10.1590/S141381232010000100018.

PREFEITURA DE CURITIBA. Autorizado início das obras do Restaurante Popular do Capanema. Curitiba, 2017. Disponível em: https://www.curitiba.pr.gov.br/noticias/autoriza do-inicio-das-obras-do-restaurante-popular-docapanema/43330. Acesso em: 15 abr. 2020.

PREFEITURA DE CURITIBA. Restaurante Popular do Capanema conquista trabalhadores dos bairros próximos. Curitiba, 2018. Disponível em: https://www.curitiba.pr.gov.br/noticias/restaura nte-popular-do-capanema-conquistatrabalhadores-dos-bairros-proximos/. Acesso em: 25 abr. 2020. 
ROSANELI, C. F. et al . A fragilidade humana diante da pobreza e da fome. Revista Bioética, Brasília, v. 23, n. 1, p. 89-97, 2015. Disponível em:

http://www.scielo.br/scielo.php?script=sci_arttex t\&pid=S1983-

$80422015000100089 \& \operatorname{lng}=e n \& n r m=i s o$. Acesso

em: $\quad 30$ jul. $2020 . \quad$ DOI:

https://doi.org/10.1590/1983-80422015231049

SEM, A. Desenvolvimento como liberdade. São

Paulo: Companhia das Letras, 2000.

SOUZA, L. J. A. A evolução dos ambientes para restaurante. 2011. Disponível em: https://www.academia.edu/34733308/DESIGN_D E_INTERIORES_A_EVOLU\%C3\%87\%C3\%830_DOS _AMBIENTES_PARA_RESTAURANTE. Acesso em: 20 abr. 2020.

VALENTE F. L. S. Fome, desnutrição e cidadania: inclusão social e direitos humanos. Saúde e Sociedade. v. 12 , n. 1, p. 51-60, 2003. DOI:

https://doi.org/10.1590/S0104-

12902003000100008.

VASCONCELOS, F. A. G. Combate à fome no Brasil: uma análise histórica de Vargas a Lula. Revista de Nutrição, Campinas, v. 18, n. 4, p. 439457, $2005 . \quad$ Disponível em: http://www.scielo.br/scielo.php?script=sci_arttex t\&pid=S1415- 52732005000400001. Acesso em: 13 mar. 2020.2 DOI:

https://doi.org/10.1590/S1415-

$\underline{52732005000400001 .}$.

VENTURI, J. L. Estudo das características empreendedora dos proprietários de restaurantes na cidade de Itapema, conforme abordagem de David McClelland. 2003. $113 \mathrm{f}$. Dissertação (Mestrado em Turismo e Hotelaria) Universidade do Vale do Itajaí, Balneário Camboriú, 2003. 